\title{
Universal Pharmacare - Redressing Social Inequities in the Canadian Health System: A Response to Recent Commentaries
}

\author{
Mohammad Hajizadeh $^{{ }^{*} \mathbb{\oplus}}$, Sterling Edmonds ${ }^{2}$
}

\begin{abstract}
*Correspondence to: Mohammad Hajizadeh, Email: m.hajizadeh@dal.ca Copyright: (c) 2021 The Author(s); Published by Kerman University of Medical Sciences. This is an open-access article distributed under the terms of the Creative Commons Attribution License (http://creativecommons.org/licenses/ by/4.0), which permits unrestricted use, distribution, and reproduction in any medium, provided the original work is properly cited.

Citation: Hajizadeh M, Edmonds S. Universal pharmacare - redressing social inequities in the Canadian health system: a response to recent commentaries. Int J Health Policy Manag. 2021;10(6):356-357. doi:10.34172/ijhpm.2020.129 Received: 1 July 2020; Accepted: 11 July 2020; ePublished: 18 July 2020
\end{abstract}

$\mathrm{W}$ e are grateful for the very interesting and insightful commentaries written by Lexchin, ${ }^{1}$ Tuohy, ${ }^{2}$ Acri née Lybecker, ${ }^{3}$ Rawson, ${ }^{4}$ and Gagnon ${ }^{5}$ in response to our editorial, "Universal Pharmacare in Canada: A Prescription for Equity in Healthcare."

In his commentary, Lexchin ${ }^{1}$ rightly highlights the numerous advantages to universal pharmacare in Canada, and that the main arguments against universal pharmacare (eg, pharmacare would be too costly, private insurance coverage would suffer, or only certain gaps in insurance coverage need filling) do not outweigh the strong arguments in favour of the regime. Tuohy ${ }^{2}$ offers a comprehensive commentary on the politics associated with pharmacare in Canada, and the similarities and differences with comparable debate in the United States and 'Medicare for all.' Likewise, Acri née Lybecker, ${ }^{3}$ drawing on the experience of the United States, makes the case that some Canadians (particularly lowerincome Canadians, seniors, the disabled, and patients with chronic disease) currently have the coverage sought under a universal pharmacare program and that other options are worth exploring. Rawson ${ }^{4}$ discusses the importance of equity in any universal pharmacare regime, and that price of drugs will play an important role in their affordability and accessibility to the Canadian public. Finally, Gagnon ${ }^{5}$ correctly highlights the inequities (unfair inequalities) and inefficiencies found in the current system and that universal pharmacare would provide better access to prescription medications, instead of simply "filling the gap" with catastrophic coverage.

We agree with Acri née Lybecker that "the devil is in the detail" and we do not discount the complexity of implementing a single-payer, universal pharmacare program in Canada. The author asserts that, although many lowincome Canadians may be struggling to pay for prescription drugs, these same low-income Canadians already have access to some form of provincial drug insurance limiting their out-of-pocket payments and that any social inequity would not be addressed by universal pharmacare anyway. We acknowledged and discussed in our editorial that significant interprovincial variation in public drug coverage has, in fact, led to corresponding variation in the burden of out-ofpocket expenses for drugs and pharmaceutical products. ${ }^{6-8}$ Residents should not have better or worse public drug coverage based solely on their province of residence, and universal pharmacare would fix that. Additionally, it should be restated that the social inequities highlighted in our editorial exist despite the existence of any provincial public drug coverage. In fact, catastrophic out-of-pocket expenses on drugs and pharmaceutical products disproportionately affect low-income households, rural households, ${ }^{6}$ seniors and households using social assistance. ${ }^{7,9,10}$ These inequities extend to those households that fall outside of the program criteria used by provincial governments to define, for instance, what a low-income household is. Our recent work on out-ofpocket payments for health care ${ }^{11}$ also indicated that many Canadians, including those who may not be poor, elderly, or using social assistance, face considerable inequities to finance their health care expenditures mainly due to the high outof-pocket costs associated with drugs and pharmaceutical products. ${ }^{11}$ The reality is that the current system does not eliminate the risk of catastrophic payments on drugs and pharmaceutical products, and universal pharmacare could reduce this risk for Canadian households.

Both Acri née Lybecker and Rawson make the case that Canada may be better off expanding private insurance for the gaps in coverage that currently exist because they offer more generous coverage and coverage for more expensive drugs that would be left out of any public plans. This view is misleading because it misunderstands the reality of drug coverage, pricing, and access to prescription medicines in Canada. ${ }^{5}$ Gagnon rightly highlights that most private drug plans cover many new, increasingly expensive drugs that offer no significant therapeutic benefit, creating wasteful coverage regimes that do nothing to address the inequity of access among Canadians. ${ }^{5,12}$ As Lexchin points out, private plans that cover more drugs are not necessarily better than those plans that cover less, ${ }^{1}$ which is another potential source of wasteful coverage. 
Several studies, ${ }^{7,9,10}$ including our recent editorial, ${ }^{6}$ suggest considerable social inequities in the burden of out-of-pocket expenses for drugs and pharmaceutical products in Canada. Patchwork public coverage with varying co-payments, deductibles, and provincial formularies burden so many Canadians, and universal pharmacare can potentially redress systemic social inequities that affect Canadian households.

Ethical issues

Not applicable.

Competing interests

Authors declare that they have no competing interests

Authors' contributions

Both authors contributed to the conception, drafting, and revising of the correspondence.

Authors' affiliations

${ }^{1}$ School of Health Administration, Dalhousie University, Halifax, NS, Canada. ${ }^{2}$ Schulich School of Law, Dalhousie University, Halifax, NS, Canada.

\section{References}

1. Lexchin J. It's time to finally kill the zombies: Comment on "Universal Pharmacare in Canada." Int J Health Policy Manag. 2020; In Press. doi:10.15171/ijhpm.2020.03

2. Tuohy $\mathrm{CH}$. Separated at birth: the politics of pharmacare for all in Canada and Medicare for all in the United States: Comment on "Universal pharmacare in Canada." Int J Health Policy Manag. 2020; In Press. doi:10.34172/ijhpm.2020.31

3. Acri née Lybecker KML. The Challenges of Canadian pharmacare are more complicated than acknowledged: Comment on "Universal pharmacare in Canada." Int J Health Policy Manag. 2020; In Press. doi:10.15171/ijhpm.2020.20
4. Rawson NSB. National pharmacare in Canada: equality or equity, accessibility or affordability: Comment on "Universal pharmacare in Canada: a prescription for equity in healthcare." Int J Health Policy Manag. 2020; In Press. doi:10.15171/ijhpm.2019.146

5. Gagnon M-A. Understanding the battle for universal pharmacare in Canada: Comment on "Universal pharmacare in Canada." Int J Health Policy Manag. 2020; In Press. doi:10.34172/ijhpm.2020.40

6. Hajizadeh M, Edmonds S. Universal pharmacare in Canada: A prescription for equity in healthcare. Int $J$ Health Policy Manag. 2020;9(3):9195. doi:10.15171/ijhpm.2019.93

7. Caldbick S, Wu X, Lynch T, Al-Khatib N, Andkhoie M, Farag M. The financial burden of out of pocket prescription drug expenses in Canada. Int J Health Econ Manag. 2015;15(3):329-338. doi:10.1007/s10754-0159171-3

8. Daw JR, Morgan SG. Stitching the gaps in the Canadian public drug coverage patchwork? A review of provincial pharmacare policy changes from 2000 to 2010. Health Policy. 2012;104(1):19-26. doi:10.1016/j. healthpol.2011.08.015

9. Advisory Council on the implementation of National Pharmacare. A Prescription for Canada: Achieving Pharmacare for All - Final Report of the Advisory Council on the Implementation of National Pharmacare. Ottawa, Ontario; 2019. https://www.canada.ca/content/dam/hc-sc/ images/corporate/about-health-canada/public-engagement/externaladvisory-bodies/implementation-national-pharmacare/final-report/finalreport.pdf.

10. Morgan SG, Martin D, Gagnon M-A, Mintzes B, Daw JR, Lexchin J. Pharmacare 2020: The Future of Drug Coverage in Canada. Vancouver: Pharmaceutical Policy Research Collaboration, University of British Columbia; 2015.

11. Edmonds S, Hajizadeh M. Assessing progressivity and catastrophic effect of out-of-pocket payments for healthcare in Canada: 2010-2015. Eur J Health Econ. 2019;20(7):1001-1011. doi:10.1007/s10198-019-01074-x

12. O'Brady S, Gagnon MA, Cassels A. Reforming private drug coverage in Canada: Inefficient drug benefit design and the barriers to change in unionized settings. Health Policy. 2015;119(2):224-231. doi:10.1016/j. healthpol.2014.11.013 